\title{
Individualized pharmacological treatment of oral mucositis pain in patients with head and neck cancer receiving radiotherapy
}

\author{
Ingrid Stenström Ling and Britt Larsson
}

\section{Linköping University Post Print}

N.B.: When citing this work, cite the original article.

The original publication is available at www.springerlink.com:

Ingrid Stenström Ling and Britt Larsson, Individualized pharmacological treatment of oral mucositis pain in patients with head and neck cancer receiving radiotherapy, 2011, Supportive Care in Cancer, (19), 9, 1343-1350.

http://dx.doi.org/10.1007/s00520-010-0955-1

Copyright: Springer Verlag (Germany) http://www.springerlink.com/

Postprint available at: Linköping University Electronic Press http://urn.kb.se/resolve?urn=urn:nbn:se:liu:diva-70215 
Individualized pharmacological treatment of oral mucositis pain in patients with head and neck cancer receiving radiotherapy

\section{Authors:}

Ingrid Stenstrom Ling, $\mathrm{RN}^{1}$, Britt Larsson $\mathrm{MD}, \mathrm{PhD}^{1,2}$

${ }^{1}$ Pain and Rehabilitation Centre, University Hospital, Linkoping, Sweden.

${ }^{2}$ Rehabilitation Medicine, Department of Clinical and Experimental Medicine, Faculty of Health Sciences, Linkoping University, Linkoping, Sweden.

Address correspondence to: Ingrid Stenstrom Ling, Pain and Rehabilitation Centre, University Hospital, SE 58185 Linkoping, Sweden. Phone number: 004610 33684. Fax number: 00461033682.

E-mail: ingrid.stenstrom.ling@lio.se.

Number of words: 4109

Number of references: 32

Number of tables: 5 


\begin{abstract}
Purpose: Pain is a prominent symptom in radiotherapy induced oral mucositis (OM). This study assesses the effect of pharmacological treatment in head and neck cancer patients with OM-induced pain and swallowing difficulties.
\end{abstract}

Methods: This study included 82 patients with head and neck cancer undergoing radiotherapy and referred to the Pain and Rehabilitation Centre at Linkoping University Hospital in Sweden because of OM-induced pain. During one week, pain assessment, onset of individually tailored choice of drugs, treatment evaluation, and adjustments, were undertaken.

Combinations of acetaminophen, non-steroid anti-inflammatory drug (NSAID) and opioids were by steps applied. To evaluate effects, the patients answered the European Organization for Research and Treatment of Cancer (EORTC) Quality of Life Questionnaire (QLQ-H\&N35) in connection with the initial pain assessment and one week later.

Results: Worsening of soreness in mouth and overall worsening of swallowing difficulties were seen in the patients referred within the third week of radiotherapy, showing increased severity of OM during the current week $(n=59)$. Pain and swallowing difficulties were unchanged in patients referred later than the third week, showing unchanged severity of OM during the current week $(n=23)$.

Conclusion: The answers to the questionnaire showed that the individualized pain treatment with systemic analgesics exploited to the highest degree was insufficient. Future development of pharmacological possibilities for treatment of OM related pain is urgent. In addition, development of structured nursing care and patient selfcare can contribute to improved pain relief.

\title{
Key words:
}

Head and neck cancer, radiotherapy, mucositis, pain, pain treatment 


\section{Introduction}

Head and neck cancer is diagnosed in about 650000 patients worldwide each year (about $6 \%$ of all cancer in the global population) [1]. Current treatments are mainly surgery, radiotherapy (RT), combination of surgery and RT, or combination of RT and chemotherapy [2]. In patients undergoing RT for head and neck cancer, oral mucositis $(\mathrm{OM})$ is the most common acute adverse effect [3]. More aggressive tumor treatment methods in recent years, above all increased use of concomitant chemotherapy, have lead to increased severity of OM [4-6] and increased mean incidence of OM (80\%) [4].

OM, a complex biological process, has been divided into five phases [7]. Several pro-inflammatory and cytotoxic factors are involved [6-8]. In the average temporal pattern, OM starts with erythema one week after RT start, coinciding with accumulated radiation dose of 10 Gray (Gy) [6-9]. Confluent erythema and ulcers are seen during the third week, coinciding with accumulated dose of $30 \mathrm{~Gy}[6,8,9]$. Ulceration proceeds during the rest of the RT period. Fibrin coated ulcers [8] and increased risk of infection [7] are to be expected. A peak of OM severity is seen in the fifth week of RT [10]. The healing process starts two to three weeks after completed RT [8], but OM may remain severe five to seven weeks after the RT period [6].

Pain is the most prominent OM symptom [3]. Mild pain arises during the first week of RT [8]. Escalation of pain is seen from about three weeks of RT [3,6] in connection with appearance of ulcers [9]. Pain persists until two to six weeks after completed RT [9]. Sometimes pain remains for six month or more [11]. Another frequent OM symptom is swallowing difficulties [3-5, 12], mainly due to pain [5], often leading to severe weight loss [5, 12] and requiring a feeding tube $[4,13]$.

Thus, OM development with pain and swallowing difficulties requires pain treatment in patients with head and neck cancer receiving RT. Topical anaesthetics against OM pain are recommended in the literature. Use of systemic analgesics is also evident, but is too briefly described for clinical use in publications focused on other aspects of OM [5, 6, 8, 9, 14-16]. Somewhat more elucidating concerning the use of systemic analgesics is the National Comprehensive Cancer network (NCCN) guidelines for mucositis prevention and management [17]. Non-opioid use for mild pain due to early erythema and opioid use for more severe pain due to ulceration are recommended $[6,8,17]$. Adjuvant medication with antidepressants and anticonvulsants is even more briefly mentioned.

To our knowledge, comprehensive and detailed clinical guidelines concerning pharmacological treatment of OM-induced pain - including pain assessment, choice of drugs, administration routes, pharmaceutical forms, and evaluation of effect - are lacking. This study was designed as a clinical series of patients treated according to clinical routine for mucositis-related pain. By the clinical series it was possible to assess the effect of a one-week step-based individualized pharmacologic regimen in head and neck cancer patients with OM-induced pain and swallowing difficulties. The hypothesis was that pain relief would be sufficiently improved in the patients by using a stepwise application of acetaminophen, NSAID, and opioids. 


\section{Subjects}

Ninety-nine patients with head and neck cancer intended for RT were referred for consultation from oncologists and oto-rhino-laryngologists to the Pain and Rehabilitation Centre at Linkoping University Hospital between 2006 and 2008 due to OM-induced pain. These 99 patients were asked to participate in the study. Eight of these patients were referred due to tumour related pain before RT. Eighty-two patients participated, as 17 patients were excluded because of communication difficulties, cognition disturbances, or denial to participate.

The study was conducted as a part of the daily medical work at the Pain Department. It was done in accordance with Swedish legislation and the patients gave their informed consent. 


\section{Methods}

\section{Procedure}

The patients were referred because of pain intensity in mouth, throat, or other locations in head and neck region of more than $30 \mathrm{~mm}$ out of $100 \mathrm{~mm}$ according to a visual analogue scale (VAS). The Department's work in this study was performed by three experienced nurses in close consultation with physicians specialized in anaesthesiology. These nurses were well informed about and trained for the procedure of assessment, intervention and evaluation. The Pain Department's physicians were responsible for the pain treatment, and there was a frequent dialogue between the physicians and the nurses administrating the interventions. In the clinical situation there was strived for pain intensity less than $30 \mathrm{~mm}$ out of $100 \mathrm{~mm}$ according to VAS for facilitated oral nutrition, minimized sleeping disturbances due to pain, and ability of patient to endure RT treatment.

The outcome of an initial pain assessment was crucial when the step-based pharmacological intervention, with systemic analgesics and topical anaesthetics as cornerstones, was tailored and started the same day. The intervention was based on the World Health Organization (WHO) analgesic ladder for cancer pain relief [18], excluding the second step in this ladder, i.e. weak opioids. A move from one step to another was taken when pain intensity was assessed more than $30 \mathrm{~mm}$ out of $100 \mathrm{~mm}$ according to VAS and/or when moderate or severe swallowing difficulties persisted according to verbal assessment. Systemic analgesics implied acetaminophen, NSAID, and strong opioids. Mainly due to tumour induced pain, antidepressants, anticonvulsants, or betametason were regularly considered. The OM severity and its expected development were considered in the treatment design. Drug administration routes and pharmaceutical forms were carefully chosen, considering swallowing ability and patient convenience. Detailed oral information and an easily comprehensible written drug schedule, revised when necessary, were given to the patient. Furthermore, by frequent dialogue between the nurses at the Pain Department and the patient, compliance to the treatment was optimized. Evaluation of effect and possible side effects was conducted every day, except weekends, of the first week. Adjustments were undertaken in dialogue with the patient.

In summary, for individualized therapy, every point in the initial pain assessment and patient's different individual conditions in the pharmacological intervention design was systematically considered, as well as repeated assessments for evaluation and possible adjustments.

Alterations in pain and swallowing difficulties are closely related to OM development. Therefore, the OM grade in patients with an irradiated mouth was noted in connection to the initial pain assessment and one week later.

The patients answered a quality of life questionnaire in connection to the initial pain assessment and one week later. These time points were denoted TQ1 and TQ2, respectively. TQ2 was an appropriate time point for reassessment, as analgesics with short half-life were consistently used and a steady state was attained at this time point, making it possible to evaluate the effect of the intervention.

\section{Initial pain assessment}

The Department's treatment of every referred patient started with a structured interview to assess the following: 
1. Location of pain

2. Duration of pain

3. Continuous or intermittent pain

4. Quality of pain according to the patient's verbal description of pain experience:

a) descriptors preferably associated with nociceptive pain: e.g., sore, dull, hurting, tender, throbbing

b) descriptors preferably associated with neuropathic pain: e.g., burning, stabbing, tingling, shooting, radiating

5. Alteration of sensibility

6. Intensity of pain, both continuous and intermittent, according to VAS.

7. Variations in pain, e.g., due to swallowing, chewing, talking, changing in body position, and variations over day and night

8. Disturbances in daily function

9. Other symptoms induced by RT, such as altered taste, xerostomia, swallowing difficulties, altered salivation, nausea, weight loss, fatigue, sleeping disturbances, speech difficulties, hoarseness, anxiety

10. Effect of current analgesics

11. Alternative methods to relieve pain, e.g., warmth, cold

12. Smoking, abuse of alcohol and illegal drugs

13. Other diseases and current drug use

In differentiating nociceptive or neuropathic pain, outcomes in especially points 3-7 and 10 were important. Notwithstanding the difficulties in evaluating the verbal descriptors of the patients, assessment was done in compliance with screening tools frequently used in clinical practice [19].

\section{Visual analogue scale}

The Visual Analogue Scale (VAS) consisted of a $100 \mathrm{~mm}$ horizontal line, anchored with "No pain" and "Worst pain imaginable". The patient was asked to mark the point on the line corresponding to the intensity of pain perceived. Recently it has been reported by Fainsinger et al (2009) [20] that pain assessed less than 3 according to the 11-point (0-10) Numeric Rating Scale (NRS), which correlates well with $30 \mathrm{~mm}$ according to VAS, is categorized as mild pain.

\section{Assessment of mucositis grade}

Assessment of OM grade according to a modified version of the WHO scale [21] was done by one trained dentist at the dental services at the hospital.

Four OM grades were used:

0 : No reaction

1: Hyperaemia, impressions, soreness, oedema

2: Erythema, occasional ulcers, soreness

3: Painful erythema, larger fibrin coated ulcers

4: Widespread ulcerated areas, easily bleeding, very painful

\section{Individualized pharmacological intervention}




\section{Acetaminophen and NSAID}

A majority of patients was regularly on treatment with acetaminophen, prescribed by the oncologists, at the initial pain assessment. As a first step, continued acetaminophen was recommended. As a second step, NSAID, preferably with short half-life, was additionally prescribed.

\section{Opioids}

As a third step, opioids were added if pain relief was insufficient with acetaminophen and NSAID. In case of severe pain, both NSAID and opioids were prescribed immediately after pain assessment. If a weak opioid was previously prescribed, a strong opioid instead was prescribed. Oral or enteral morphine and transdermal fentanyl were preferred. Expected opioid adverse effects always were prevented, preferably prophylaxis against nausea/vomiting and constipation. Optimal individual opioid dosage was strived for, by regular administration of a short acting opioid and by adding a rescue dose, for one or two days. The aim was best possible pain relief according to stipulated goals (section Procedure above) and negligible or acceptable side effects. Daily opioid doses ranged from $40 \mathrm{mg}$ to $160 \mathrm{mg}$ equivalent to morphine between TQ1 and TQ2. When optimal dosage was attained, exchange to a slow release opioid was undertaken. Additionally, a short acting opioid was prescribed as rescue dose against breakthrough pain and as pain prevention, primarily administered before meals.

\section{Adjuvant medication}

As a fourth step, amitryptilin, gabapentin, or pregabalin were considered due to neuropathic pain, mainly tumour related. Betametason was considered for optimized anti-inflammatory effect, impaired general condition, or antiemetic effect.

\section{Topically acting drugs}

Lidocain and benzydamine were prescribed at RT-start by the dental services at the hospital to all patients with an irradiated mouth at the RT start. Continued use was requested and supported by the dental services and by the nurses from the Pain Department.

\section{Assessment of pain and swallowing difficulties according to the Quality of Life Questionnaire Head and Neck 35 (EORTC QLQ-H\&N35)}

A diagnosis specific module of quality of life questionnaire for head and neck cancer patients (QLQ-H\&N35) designed by The European Organization for Research and Treatment of Cancer (EORTC) was used for clinical evaluation $[22,23]$. The module is a self-administrated questionnaire comprising 35 questions concerning pain (nos. 31-34), swallowing (nos. 35-38, 49), other physical symptoms, and psychological and social function. Thirty questions assess symptoms or claims using one of four grades: "not at all”, "a little", "quite a bit", or "very much". Five questions require "yes" or "no" answers. Data concerning pain and swallowing are presented in this study.

\section{Outcomes}

The primary outcome of the study was pain relief according to the EORTC QLQ-H\&N35. The secondary outcome was decreased swallowing difficulties according to the EORTC QLQ-H\&N35. 


\section{Statistics}

Wilcoxon Signed Ranks Test was used for pair-wise calculations. P-values $<0.05$ were considered to indicate statistical significance. The Statistical Package for the Social Sciences version 17.0 was used for all analyses. 


\section{Results}

\section{Dichotomization in early and late intervention groups}

Pharmacological pain treatment intervention was started at different time points during RT as the patients were referred as soon as pain intensity exceeded $30 \mathrm{~mm}$ on VAS. The 82 subjects were divided in an early intervention group (EI) and a late intervention group (LI). Intervention for the EI group (59 patients, mean age 63 years (SD 11), 20 (34\%) women) started before RT (eight patients with tumour-related pain) or during week 1-3 of RT, while the intervention for the LI group (23 patients, mean age 66 years (SD 11), 7 (30\%) women) started after week three of RT.

\section{Tumour location and staging, tumour treatment and mucositis grade}

Tumour location and classification according tumour, node, and metastasis (TNM) staging system are shown in Table 1. Data for TNM staging was missing for one patient (4\%) in LI group. Proportion of larynx tumours was $14 \%$ in EI group and $31 \%$ in LI group. Five $(63 \%)$ of the larynx tumours in EI group were in stage I and II according to TNM classification, whereas the seven larynx tumours in LI group were all (100\%) in stage I and II. In the EI group, other tumours comprised 15\%; in the LI group, other tumours comprised $4 \%$.

Tumour treatment, chosen considering tumour type, location, size, spreading, and possible metastases, is shown in Table 2. RT given as standard fractionation was preferably chosen. The distribution of all types of RT treatments was rather similar in both groups.

In the EI group, the OM grade increased between TQ1 and TQ2 (1.6, standard deviation (SD) 1.3, to 2.2, SD 1.1, p-value <0.001). In the LI group, the OM grade was unchanged between TQ1 and TQ2 (2.6, SD 0.9, and 2.9, SD 0.9, respectively, p-value 0.059). Thus, at both TQ1 and TQ2 the OM grade was higher in the LI group than in the EI group (p-values 0.002 and 0.033 , respectively).

\section{Pharmacological interventions}

Pharmacological interventions during the week between TQ1 and TQ2 are summarized in Table 3. The pharmacological interventions were rather similar in both groups. Because of likely tumour-related neuropathic pain, amitryptilin was added for one patient in the EI group and pregabalin was added for one patient in the same group.

\section{Pain and swallowing difficulties reported in EORTC QLQ-H\&N35}

Forty-seven patients in the EI group and 19 patients in the LI group answered the questionnaire at both TQ1 and TQ2. The answers on pain and swallowing questions are presented in Table 4. In the EI group, the pain question about soreness in the mouth showed unexpectedly significant worsening between TQ1 to TQ2. Significant worsening was also the case for the three swallowing questions about liquids and solid food, choking when swallowing, and for the mean score for the five swallowing questions. For the remaining three questions about pain and the remaining two questions about swallowing difficulties, no significant differences were seen between 
TQ1 and TQ2. In the LI group, there were no significant differences between TQ1 and TQ2, neither concerning pain questions nor concerning swallowing questions.

Proportions of patients who reported improvement or worsening in pain and swallowing difficulties for at least one of four grades ("not at all", "a little", "quite a bit", or "very much"), or who reported no change between TQ1 and TQ2 are shown in Table 5. The majority of patients in both groups reported unchanged pain and swallowing difficulties. Missing answers to single questions, either at TQ1 or TQ2 or at both tQ1 and TQ2, in the questionnaire, are presented in "Missing data", mean proportion $22 \%$ in the EI group and $23 \%$ in the LI group. 


\section{Discussion}

The individualized pharmacological treatment did not result in sufficient relief of pain or swallowing difficulties despite exploiting systemic analgesics and topical anaesthetics to the utmost during the first week of advanced OM pain treatment in patients undergoing RT. We even noticed worsening of complaints in the EI group, concerning soreness in mouth as well as swallowing difficulties overall, probably due to parallel OM development.

The hypothesis for the study was that pain relief would be sufficiently improved by using a stepwise application of acetaminophen, NSAID, and opioids. This hypothesis, tested by comparing pain and swallowing difficulties according to EORTC QLQ-H\&N35 at start of pain treatment and one week later, Table 4, has to be rejected.

In two recent reviews, not mainly addressed to pain treatment, it is incidentally proposed that systemic analgesics may insufficiently provide pain relief [3,9]. Also in three recent clinical studies on different aspects of OM insufficient pain relief with systemic analgesics is mentioned [24-26]. However, the advantage of this study - a structured individualized intervention with acetaminophen, NSAID, opioids, and topical anaesthetics is that it clearly, for the first time to our knowledge, illustrates extensive difficulties achieving improved pain relief for the patient group studied (Tables 4 and 5).

The referral criterion; pain intensity exceeding $30 \mathrm{~mm}$ on VAS, entailed a heterogeneous sample according to the time for intervention. To handle the sample, we retrospectively dichotomized the patients in early and late intervention groups. The dichotomization is supported by the literature, suggesting that need of treatment with systemic analgesics mainly arises within the third week of RT [6]. A peak, 27 of 59 patients in the EI group, of patients in need of advanced pain intervention during exactly that third week of RT was observed in this study. By the dichotomizing in early and late referred subjects, it was also possible to compare the effect of early pain intervention and late pain intervention.

In the EI group, the pain intervention was done in parallel with significantly increased OM severity between TQ1 and TQ2, the latter possibly contributing to the worsened or unchanged pain and swallowing difficulties (Table 5). The OM grade in the LI group was unchanged between TQ1 and TQ2 and higher than in the EI group at both times. However, the pain treatment in the LI group was not as insufficient as in the EI group, inasmuch as at least no worsening of soreness in the mouth and no worsening of mean score for swallowing questions was seen.

On the whole, successful outcome of pain treatment was not attained in any of the groups. On the other hand, without the apparently insufficient pain treatment in this study, the extent of problems related to severe pain probably would have been still worse during RT. Consequences of severe pain and swallowing difficulties probably would have resulted in even more undesired breaks in RT and more hospitalizations, both frequent results reported in the literature $[3,5,9,16]$. The relief in pain and swallowing difficulties achieved in a minority of patients between TQ1 and TQ2 (Table 5) would probably not have been realized without our interventions. 
Retrospectively, we noted that due to supposed neuropathic OM pain, gabapentin or pregabalin were added after TQ2 for some of the patients. It is well known that nociceptive and inflammatory mechanisms are involved in OM pain $[3,11,25]$. Treatment of nociceptive pain mostly can be performed with a straightforward design. Recently, it has been established that neuropathic pain due to OM also is common [3, 11]. Neuropathic pain is not sensible for analgesics, and topical anaesthetics have too short duration. Instead, treatment with antidepressants or anticonvulsants is necessary [18]. Onset and dose escalation until acceptable pain relief require at least as much as a couple of weeks. Thus, an extended time period had been necessary for evaluation of the intervention with adjuvant medication, which in this clinical series was primary intended for tumour related neuropathic pain and not for OM pain, as mentioned in section Methods, Procedure. However, in this study the intervention between TQ1 and TQ2 in fact appeared to be treatment with systemic analgesics due to nociceptive pain. Enough attention was possibly not directed to different current and expected pain mechanisms $[3,11,25]$. We agree with the recent publications $[3,11,25]$ suggesting use of adjuvant medication more frequently and earlier in OM development in order to attain improved pain relief. In a recent study Bar Ad et al (2009) [27] stated, that gabapentin appeared to be promising in reducing the need of opioids for patients with OM pain, which indicates that the role of gabapentin in OM pain therapy ought to be studied.

Swallowing difficulties remained unchanged or increased for a majority of the patients (Tables 4 and 5). More severe pain associated with increased swallowing difficulties is reported in a recent study [24]. For optimal nutrition, continuous nursing support and education concerning adjusted diet and nutritional supplements are essential [13]. Prophylactic placement of percutaneous endoscopic gastrostomy (PEG) feeding tube has been recommended to ensure sufficient nutrition and thereby prevent unwanted RT-breaks and hospitalizations due to severe weight loss $[5,16,28]$. Using PEG feeding tube may also imply pain relief. Patients with PEG can avoid frequent painful and pain triggering swallowing. Furthermore, the PEG offers an alternative administration route for almost all oral medication.

Frequent basic oral care is considered to reduce duration and severity of OM [12,14, 29, 30]. The use of current clinical guidelines facilitates structured care [14, 29]. Nursing support and frequent patient self-care contribute to reduced duration and severity of OM pain [30].

Nursing care is important for overall improved management in this patient group [31]. By improving nursebased patient education, support, and dialogue, the ability of the patients to cope with pain and swallowing difficulties may be improved [26, 32].

\section{Methodological considerations}

Without any comparison group, a number of unidentified confounding factors are likely to be present, which is a major concern in the interpretation of the results. Furthermore, a majority of subjects not eligible at RT-start, a heterogeneous clinical picture at onset of pain treatment and the short observation time are limitations which have to be considered when the results are interpreted. 
Mean proportion for missing answers, and thus, also a missing possibility to make the Wilcoxon Signed Ranks Test, reached $22 \%$ in the EI group and $23 \%$ in the LI group. This considerable proportion of missing data might be caused by limited willingness of patients with less pain or swallowing difficulties to answer the EORTC QLQ-H\&N35 completely. However, it is difficult to assess the significance of the missing data in the interpretation of the results.

Patients with larynx tumour differed from other tumours (Table 1) regarding target area of RT. Without an irradiated mouth, they had no mucosal injury located in the mouth, but they did have it located in the larynx area. It is reasonable to suspect that the answers from larynx patients in both groups decreased mean score for pain and soreness in mouth, but increased mean score for painful throat. The main results, however, were probably not influenced.

\section{Conclusion and Clinical Implications}

Despite transparent individualized interventions with systemic analgesics, it was shown in this clinical series of patients with head and neck cancer undergoing RT, that OM pain treatment was insufficient. The clinical implications of the results are that careful and repeated attention has to be directed to current and expected pain mechanisms. When systematic analgesics do not provide sufficient OM pain relief, we suggest, according to our very limited clinical experience and to the recent publication of Bar Ad et al (2009) [27], and in absence of other possibilities at present, that additional treatment with gabapentin or pregabalin might be tried. However, the effect of gabapentin and pregabalin on OM pain has to be evaluated in carefully designed studies. Parallel to development of pharmacological pain treatment it is valuable to further investigate how structured nursing support and patient self-care can contribute to improved pain relief. 


\section{References}

1. Argiris A, Karamouzis MV, Raben D, Ferris RL (2008) Head and neck cancer. Lancet 371:1695-1709

2. Scully C, Bagan J (2009) Oral squamous cell carcinoma overview. Oral Oncol 45:301-308. doi:10.1016/j.oraloncology.2009.01.004

3. Epstein JB, Elad S, Eliav E, Jurevic R, Benoliel R (2007) Orofacial pain in cancer: Part II - Clinical perspectives and management. J Dent Res 86(6):506-518. doi: 10.1177/154405910708600605

4. Trotti A, Bellm LA, Epstein JB, Frame D, Fuchs HJ, Gwede CK, Komaroff E, Nalysnyk L, Zilberberg M (2003) Mucositis incidence, severity and associated outcomes in patients with head and neck cancer receiving radiotherapy with or without chemotherapy: a systematic literature review. Radiother Oncol 66(3):253-262. doi:10.1016/S0167-8140(02)00404-8

5. Lalla RV, Sonis ST, Peterson DE (2008) Management of oral mucositis in patients with cancer. Dent Clin North Am 52(1):61-77, viii

6. Scully C, Sonis S, Diz PD (2006) Oral mucositis. Oral Dis 12(3):229-241. doi:10.1111/j.16010825.2006.01258.x

7. Sonis ST, Elting LS, Keefe D et al (2004) Perspectives on cancer therapy-induced mucosal injury, pathogenesis, measurement, epidemiology, and consequences for patients. Cancer 100(9 Suppl):1995-2025. doi: 10.1002/cncr.20162

8. Treister N, Sonis S (2007) Mucositis: biology and management. Curr Opin Otolaryngol Head Neck Surg 15:123-129

9. Napenas JJ, Shetty KV, Streckfus CF (2007) Oral mucositis: Review of pathogenesis, diagnosis, prevention and management. Gen Dent 55(4):335-344

10. Elting LS, Cooksley CD, Chambers MS, Garden AS (2007) Risk, outcomes and costs of radiationinduced oral mucositis among patients with head-and-neck malignancies. Int J Radiat Oncol Biol Phys 68(4):1110-1120. doi:10.1016/j.ijrobp.2007.01.053

11. Benoliel R, Epstein J, Eliav E, Jurevic R, Elad S (2007) Orofacial pain in cancer: Part I - Mechanisms. J Dent Res 86(6):491-505. doi: 10.1177/154405910708600604

12. Rosenthal DI, Trotti A (2009) Strategies for managing radiation-induced mucositis in head and neck cancer. Semin Radiat Oncol (19):29-34. doi:10.1016/j.semradonc.2008.09.006

13. Raykher A, Russo L, Schattner M et al (2007) Enteral nutrition support of head and neck cancer patients. Nutr Clin Pract 22(1):68-73. doi: 10.1177/011542650702200168

14. Rubenstein EB, Peterson DE, Schubert et al (2004) Clinical practice guidelines for the prevention and treatment of cancer therapy-induced oral and gastrointestinal mucositis. Cancer 100(9):2026-2046. doi: 10.1002/cncr.20163

15. Silverman S (2007) Diagnosis and management of oral mucositis. J Support Oncol 5(2, Suppl 1):13-21.

16. Russo G, Haddad R, Posner M, Machtay M (2008) Radiation treatment breaks and ulcerative mucositis in head and neck cancer. Oncologist 13(8):886-898. doi: 10.1634/theoncologist.2008-0024

17. Bensinger W, Schubert M, Ang K-K, Brizel D, Brown E, Eilers J, Elting L, Mittal B, Schattner M, Spielberger R, Treister N, Trotti A (2008) NCCN Task Force Report. Prevention and management of mucositis in cancer care. J Natl Compr Canc Netw. Jan;6 Suppl 1:S1-21; quiz S22-4

18. Laird B, Colvin L, Fallon M (2008) Management of cancer pain: basic principles and neuropathic cancer pain. Eur J Cancer. 44(8):1078-82. doi:10.1016/j.ejca.2008.03.022

19. Bennett MI, Attal N, Backonja M, Baron R, Bouhassira D, Freynhagen R, Scholz J, Tölle TR, Wittchen H-U, Staehelin Jensen T (2007) Using screening tools to identify neuropathic pain. Pain 127(3):199203. doi:10.1016/j.pain.2006.10.034

20. Fainsinger RL, Fairchild A, Nekolaichuk C, Lawlor P, Lowe S, Hanson J (2009) Is pain intensity a predictor of the complexity of cancer pain management? J Clin Oncol 27(4):585-90. doi:10.1200/JCO.2008.17.1660

21. World Health Organization (1979) Handbook for reporting results of cancer treatment. Geneva, Switzerland, pp15-22

22. Bjordal K, Hammerlid E, Ahlner-Elmqvist M et al (1999) Quality of life in head and neck cancer patients: validation of the European organization for Research and Treatment of Cancer Quality of Life Questionnaire-H\&N35. J Clin Oncol 17(3):1008-1019

23. Sherman AC, Simonton S, Adams DC et al (2000) Assessing quality of life in patients with head and neck cancer: cross-validation of the European Organization for Research and Treatment of Cancer (EORTC) Quality of Life Head and Neck module (QLQ-H\&N35). Arch Otolaryngol Head Neck Surg 126(4):459-67

24. Murphy B, MD, Beaumont J, Isitt J, Garden AS, Gwede CK, Trotti AM, Meridith RF, Epstein JB, Le Q-T, Brizel DM, Bellm LA, Wells N, Cella D (2009) Mucositis-related morbidity and resource utilization in head and neck cancer patients receiving radiation therapy with or without chemotherapy. J Pain Symptom Manage 38(4):522-532. doi:10.1016/j.jpainsymman.2008.12.004 
25. Epstein JB, Wilkie DJ, Fischer DJ, Kim Y, Villines D (2009) Neuropathic and nociceptive pain in head and neck cancer patients receiving radiation therapy. Head Neck Oncol 1(1):26:1-12. doi: 10.1186/1758-3284-1-26

26. Wong PC, Dodd MJ, Miaskowski C, Paul SM, Bank KA, Shiba GH, Facione N (2006) Mucositis pain induced by radiation therapy: prevalence, severity, and use of self-care behaviours. J Pain Symptom Manage 32(1):27-37. doi: 10.1016/j.jpainsymman.2005.12.020

27. Bar Ad V, Weinstein G, Dutta PR, Chalian A, Both S, Quon H (2009) Gabapentin for the treatment of pain related to radiation-induced mucositis in patients with head and neck tumors treated with intensitymodulated radiation therapy. Head Neck 32(2):173-177. doi:10:1002/hed.21165

28. Raykher A, Correa L, Russo L et al (2009) The role of pretreatment percutaneous endoscopic gastrostomy in facilitating therapy of head and neck cancer and optimizing the body mass index of the obese patient. J Parenter Enteral Nutr 33(4):404-410. doi: 10.1177/0148607108327525

29. McGuire DB, Correa ME, Johnson J, Wienandts P (2006) The role of basic oral care and good clinical practice principles in the management of oral mucositis. Support Care Cancer 14:541-547. doi: 10.1007/s00520-006-0051-8

30. Harris D, Eilers J, Harriman A et al (2008) Putting evidence into practice: Evidence-Based Interventions for the Management of Oral Mucositis. Clin J Oncol Nurs 12(1):141-52. doi: 10.1188/08.CJON.141-152

31. Armstrong JA, McCaffrey R (2005) The effects of mucositis on quality of life in patients with head and neck cancer. Clin J Oncol Nurs 10(1):53-56. doi: 10.1188/06.CJON.53-56

32. Wells M, Donnan PT, Sharp L et al (2008) A study to evaluate nurse-led on-treatment review for patients undergoing radiotherapy for head and neck cancer. J Clin Nurs 17(11):1428-39. doi: 10.1111/j.1365-2702.2007.01976.x 
Table 1. Location of tumour and TNM staging in the two subgroups of patients (EI, $n=59 ; \mathrm{LI}, \mathrm{n}=23$ ).

\begin{tabular}{|c|c|c|c|c|c|c|c|c|c|c|}
\hline & \multicolumn{5}{|c|}{ EI group } & \multicolumn{5}{|c|}{ LI group } \\
\hline & I & II & III & IV & Total & I & II & III & IV & Total \\
\hline & $\%(n)$ & $\%(n)$ & $\%(n)$ & $\%(n)$ & $\%(n)$ & $\%(n)$ & $\%(n)$ & $\%(n)$ & $\%(n)$ & $\%(n)$ \\
\hline $\begin{array}{l}\text { Oral } \\
\text { cavity }\end{array}$ & $5(3)$ & $3(2)$ & $12(7)$ & $10(6)$ & $30(18)$ & $4(1)$ & $4(1)$ & $0(0)$ & $17(4)$ & $26(6)$ \\
\hline Pharynx* & $2(1)$ & $5(3)$ & $7(4)$ & 27 (16) & $41(24)$ & $0(0)$ & $0(0)$ & $17(4)$ & $17(4)$ & $35(8)$ \\
\hline Larynx & $7(4)$ & $2(1)$ & $2(1)$ & $3(2)$ & $14(8)$ & $22(5)$ & $9(2)$ & $0(0)$ & $0(0)$ & $31(7)$ \\
\hline $\begin{array}{l}\text { Other } * * \\
\text { tumours }\end{array}$ & $2(1)$ & $0(0)$ & $5(3)$ & $8(5)$ & $15(9)$ & $0(0)$ & $0(0)$ & $0(0)$ & $4(1)$ & $4(1)$ \\
\hline Total & $15(9)$ & $10(6)$ & $26(15)$ & 49 (29) & $100(59)$ & $26(6)$ & $13(3)$ & $17(4)$ & 39 (9) & $96(22)$ \\
\hline
\end{tabular}

* Oro-, hypo-, and nasopharynx

** Salivary glands, nose and sinuses, unknown primary tumour with metastases to neck nodes 
Table 2. Type of radiotherapy in the two subgroups of patients (EI, $\mathrm{n}=59 ; \mathrm{LI}, \mathrm{n}=23$ ).

\begin{tabular}{lccc}
\hline & EI group & & LI group \\
& $\%(\mathbf{n})$ & & $\%(\mathbf{n})$ \\
\cline { 2 - 2 } Primary RT, standard fractionation & $62(37)$ & & $74(17)$ \\
Primary RT, altered fractionation & $9(5)$ & & $4(1)$ \\
Preoperative RT & $17(10)$ & & $9(2)$ \\
Postoperative RT & $9(5)$ & & $13(3)$ \\
RT and concomitant chemotherapy & $3(2)$ & & $0(0)$ \\
\hline
\end{tabular}


Table 3. Pharmacological interventions during the week between TQ1 and TQ2 in the two subgroups of patients (EI, $\mathrm{n}=59 ; \mathrm{LI}, \mathrm{n}=23$ ).

\begin{tabular}{lccc}
\hline & $\begin{array}{c}\text { EI group } \\
\boldsymbol{\%}(\mathbf{n})\end{array}$ & & $\begin{array}{c}\text { LI group } \\
\boldsymbol{\%}(\mathbf{n})\end{array}$ \\
\cline { 2 - 2 } NSAID added & $5(3)$ & & $0(0)$ \\
Concomitant NSAID, opioid added* & $20(12)$ & & $17(4)$ \\
NSAID and opioid added* & $41(24)$ & $35(8)$ \\
Opioid added* & $34(20)$ & $48(11)$ \\
\hline * Includes onset or increased dose of strong opioid and weak opioid \\
changed to strong opioid
\end{tabular}


Table 4. Mean values (+1SD) of pain and swallowing difficulties in the two subgroups of patients. The statistical comparisons for each group between TQ1 and TQ2 (EI, $\mathrm{n}=47 ; \mathrm{LI}, \mathrm{n}=19$ ).

\begin{tabular}{|c|c|c|c|c|c|c|}
\hline & \multicolumn{3}{|c|}{ EI group } & \multicolumn{3}{|c|}{ LI group } \\
\hline & $\begin{array}{c}\text { TQ1 } \\
\text { Mean } \\
\text { (SD) }\end{array}$ & $\begin{array}{c}\text { TQ2 } \\
\text { Mean } \\
\text { (SD) }\end{array}$ & $\begin{array}{c}\text { Statistical } \\
\text { analysis } \\
\text { p-value }\end{array}$ & $\begin{array}{c}\text { TQ1 } \\
\text { Mean } \\
\text { (SD) }\end{array}$ & $\begin{array}{c}\text { TQ2 } \\
\text { Mean } \\
\text { (SD) }\end{array}$ & $\begin{array}{c}\text { Statistical } \\
\text { analysis } \\
\text { p-value }\end{array}$ \\
\hline \multicolumn{7}{|l|}{ PAIN } \\
\hline Pain in mouth & $2.5(1.1)$ & $2.7(0.9)$ & 0.405 & $2.4(1.2)$ & $2.5(1.1)$ & 0.890 \\
\hline Pain in jaw & $1.7(0.8)$ & $1.7(0.8)$ & 0.737 & $1.6(0.8)$ & $1.7(1.0)$ & 0.157 \\
\hline Soreness in mouth & $2.3(0.9)$ & $2.8(1.0)$ & 0.001 & $2.3(1.1)$ & $2.4(1.1)$ & 0.851 \\
\hline Painful throat & $2.6(1.1)$ & $2.7(0.9)$ & 0.857 & $3.1(0.9)$ & $3.0(1.0)$ & 1.000 \\
\hline Mean & $2.3(0.8)$ & $2.5(0.7)$ & 0.286 & $2.3(0.7)$ & $2.5(0.8)$ & 0.734 \\
\hline \multicolumn{7}{|l|}{ SWALLOWING } \\
\hline Swallowing liquids & $1.8(1.0)$ & $2.3(1.1)$ & 0.007 & $2.2(1.0)$ & $2.2(0.9)$ & 0.527 \\
\hline Swallowing pureed food & $2.1(1.1)$ & $2.5(1.0)$ & 0.110 & $2.6(1.0)$ & $2.3(1.0)$ & 0.792 \\
\hline Swallowing solid food & $2.7(1.2)$ & $3.3(0.8)$ & 0.004 & $3.1(1.0)$ & $3.2(0.9)$ & 0.470 \\
\hline Choked when swallowing & $1.5(0.8)$ & $1.8(1.1)$ & 0.018 & $2.0(1.2)$ & $2.1(1.1)$ & 0.856 \\
\hline Trouble eating & $2.6(1.1)$ & $2.9(0.9)$ & 0.596 & $2.9(1.1)$ & $3.0(0.9)$ & 0.655 \\
\hline Mean & $2.1(0.9)$ & $2.6(0.8)$ & 0.016 & $2.5(0.8)$ & $2.6(0.8)$ & 0.835 \\
\hline
\end{tabular}

* 1=Not at all, 2=A little, 3=Quite a bit, 4=Very much 
Table 5. Distributions of alterations (three classes: Improvement, No change, or Worsening) in pain and swallowing difficulties at least one grade or no change in QLQ-H\&N35 between TQ1 and TQ2 in the two subgroups of patients (EI group $n=47$; LI group $n=19$ ). The variable Missing represents question not answered at TQ1 or TQ2.

\begin{tabular}{|c|c|c|c|c|c|c|c|c|}
\hline & \multicolumn{4}{|c|}{ EI group } & \multicolumn{4}{|c|}{ LI group } \\
\hline & $\begin{array}{c}\text { Improve- } \\
\text { ment } \\
\%(n) \\
\end{array}$ & $\begin{array}{c}\text { No } \\
\text { change } \\
\%(\mathbf{n}) \\
\end{array}$ & $\begin{array}{c}\text { Worse- } \\
\text { ning } \\
\%(n) \\
\end{array}$ & $\begin{array}{c}\text { Missing } \\
\%(n)\end{array}$ & $\begin{array}{c}\text { Improve- } \\
\text { ment } \\
\%(n) \\
\end{array}$ & $\begin{array}{c}\text { No } \\
\text { change } \\
\%(\mathbf{n}) \\
\end{array}$ & $\begin{array}{c}\text { Worse- } \\
\text { ning } \\
\%(n) \\
\end{array}$ & $\begin{array}{c}\text { Missing } \\
\% \text { (n) }\end{array}$ \\
\hline \multicolumn{9}{|l|}{ PAIN } \\
\hline Pain in mouth & $17(10)$ & $42(25)$ & $22(13)$ & $19(11)$ & $13(3)$ & $52(12)$ & $9(2)$ & $26(6)$ \\
\hline Pain in jaw & $22(13)$ & $39(23)$ & 17 (10) & $22(13)$ & $4(1)$ & $57(13)$ & $17(4)$ & $22(5)$ \\
\hline Soreness in mouth & $9(5)$ & $32(19)$ & $37(22)$ & $22(13)$ & $26(6)$ & $39(9)$ & $13(3)$ & $22(5)$ \\
\hline Painful throat & $20(12)$ & $39(23)$ & $20(12)$ & $21(12)$ & $26(6)$ & $30(7)$ & $26(6)$ & $18(4)$ \\
\hline \multicolumn{9}{|l|}{ SWALLOWING } \\
\hline Swallow liquids & $7(4)$ & $44(26)$ & $27(16)$ & $22(13)$ & $18(4)$ & $30(7)$ & $26(6)$ & $26(6)$ \\
\hline $\begin{array}{l}\text { Swallow pureed } \\
\text { food }\end{array}$ & $10(6)$ & $39(23)$ & $25(15)$ & $26(15)$ & $17(4)$ & $44(10)$ & $13(3)$ & $26(6)$ \\
\hline $\begin{array}{l}\text { Swallow solid } \\
\text { food }\end{array}$ & $10(6)$ & $37(22)$ & $29(17)$ & $24(14)$ & $13(3)$ & $43(10)$ & $22(5)$ & $22(5)$ \\
\hline $\begin{array}{l}\text { Choked when } \\
\text { swallowing }\end{array}$ & $5(3)$ & $53(31)$ & $22(13)$ & $20(12)$ & $26(6)$ & $30(7)$ & $22(5)$ & $22(5)$ \\
\hline Trouble eating & $27(16)$ & $29(17)$ & $22(13)$ & $22(13)$ & $22(5)$ & $26(6)$ & $30(7)$ & $22(5)$ \\
\hline
\end{tabular}

